\title{
CORRIGENDA: "A numerical technique for the solution of singular integral equations of the second kind"
}

\section{BY}

\author{
G. R. MILLER and L. M. KEER
}

(Quart. Appl. Math. 42, 455-465 (1985))

The authors have discovered an error in this paper. Equation 25 on page 459 should read as follows.

$$
\begin{aligned}
\sum_{j=1}^{\infty} \frac{(\alpha)_{j}}{(j) j !}=\frac{1}{1-\alpha}-(1-\alpha)\left\{\sum_{k=2}^{m} Q_{k}(-1)^{k}(1-a)^{k-2}\right. \\
\left.(1-a)^{m-2}(-1)^{m} \sum_{n=1}^{\infty}\left\{1 /\left[n^{m-1}(1-\alpha+n)\right]-1 / n^{m}\right\}\right\} .
\end{aligned}
$$

